\title{
Functionality and Application of Dietary Fiber in Meat Products
}

\author{
Hyun Jung Kim and Hyun-Dong Paik ${ }^{1 *}$ \\ Department of Food Bioengineering, Jeju National University, Jeju 690-756, Korea \\ ${ }^{1}$ Division of Animal Life Science, Konkuk University, Seoul 143-701, Korea
}

\begin{abstract}
Dietary fiber naturally present in various sources of cereals, legumes, fruits and vegetables plays a physiological role in human health, such as lowering cholesterol and blood pressure, improving blood glucose control in diabetes, helping with weight loss and management, and reducing cancer risk. In addition, dietary fibers have has been added as a functional food ingredient to food products to provide water-holding capacity, viscosity, gel-forming ability, and fat-binding capacity to food products. These beneficial characteristics of dietary fiber components can improve the image of meat products to be healthy and functional food products. This article reviews the concept and current definition of dietary fibers in food products along with their health benefits and functional characteristics. Dietary fibers from different sources like cereals, legumes, fruits, and vegetables and soluble dietary fibers have been applied as functional ingredients to various types of meat products, such as beef patties, ground beef and pork, pork and chicken sausages, meatballs, and jerky etc. Based on the application of dietary fibers to different types of meat products, possible future characteristics in selecting appropriate dietary fiber ingredients and their proper incorporation are explored to develop and produce healthy and functional meat products with high dietary fiber contents.
\end{abstract}

Key words: dietary fiber, meat product, functional property

\section{Introduction}

Dietary fiber is the non-digestible form of carbohydrates and lignin. Consumption of dietary fiber provides a feeling of fullness and promotes healthy laxation (Anderson et al., 2004). Specially, increased consumption of dietary fiber lowers serum lipid concentrations and blood pressure, improves blood glucose control in diabetes, and aids in weight loss by increasing satiety (Anderson et al., 2004; Anderson et al., 2009; Keenan et al., 2002). Current recommendations for dietary fiber intake are 25 $\mathrm{g} / \mathrm{d}$ for women and $38 \mathrm{~g} / \mathrm{d}$ for men in the United States (USDA, 2010) and $20 \mathrm{~g} / \mathrm{d}$ for women and $25 \mathrm{~g} / \mathrm{d}$ for men in Korea (KNS, 2010). However, most people consume less than half the recommended level of dietary fiber daily regardless of the widely acknowledged nutritional health benefits of dietary fiber consumption. The growing interest of consumers and food scientists about dietary fiber has encouraged developing high-fiber food products that provide the recommended level of dietary fiber.

*Corresponding author: Hyun-Dong Paik, Division of Animal Life Science, Konkuk University, Seoul 143-701, Korea. Tel: 822-2049-6011, Fax: 82-2-455-3082, E-mail: hdpaik@konkuk.ac.kr
Meat and meat products have both positive and negative effects on health in the diet. They are important sources of protein and essential amino acids with high biological value and essential fats, vitamins $\mathrm{A}$ and $\mathrm{B}$, and minerals (Biesalski, 2005). However, meat and meat products are often considered negative due to high levels of saturated fats, cholesterol, sodium, and nitrite (Jimenez-Colmenero et al., 2001). Some of these negative aspects in meat and meat products could be reduced by selection of lean meat cuts, removal of fats and cholesterol, dietary feed supplementation to alter fatty acid composition and decrease fat and cholesterol contents of meat, and replacement of sodium and nitrite (Decker and Park, 2010). In addition, the nutritional profile of meat products could be further improved by addition of potentially health promoting ingredients. Dietary fiber as a functional ingredient can be incorporated with meat products to improve health view of meat products. The addition of dietary fiber to meat products has been successfully used in improving cooking yield, reducing fat contents, and enhancing texture (Cofrades et al., 2000; Mendoza et al., 2001). Various types of dietary fibers have been studied for formulations of meat products such as frankfurters, dry fermented sausages, and beef patties (Chang and Carpenter, 1997; Men- 
doza et al., 2001; Pinero et al., 2008). The objective of this article was to review sources, health benefits, and functional properties of dietary fibers as functional ingredients along with their application to meat products.

\section{Dietary fiber}

Dietary fiber has highly complex substances that can be described as any non-digestible carbohydrates and lignin not digested in small intestine. The definition of dietary fiber has been revised several times since it was first defined by Hipsly in 1953 (Buttriss and Stokes, 2008). The widely accepted definition by the American Association of Cereal Chemists (AACC) states: "Dietary fiber is the remnants of the edible parts of plants or analogous carbohydrates that are resistant to digestion and absorption in the human small intestine with complete or partial fermentation in the large intestine. Dietary fiber includes polysaccharides, oligosaccharides, lignin, and associated plant substances. Dietary fibers promote beneficial physiological effects including laxation, and/or blood cholesterol attenuation, and/or blood glucose attenuation" (AACC, 2001). This definition provides a balance between the analytical methods used to quantify dietary fiber in foods and the biological and physiological effects of fiber.

Dietary fiber is available in the human diet through a wide variety of food sources, such as both raw and pro- cessed cereals, legumes, fruits and vegetables (Table 1). It is important to understand the functional attributes of the various available fiber sources. In order to better understand the functional properties of dietary fiber, it is helpful to categorize the dietary fibers into groups. Dietary fibers are classified by their relative solubility in water. Fibers that are composed of cellulose, hemicellulose, and lignin are primarily insoluble and those that include substantial portions of gums, polysaccharides, and pectin are soluble dietary fiber. Depending on their solubility, the physiological effects of dietary fibers are different (Fig. 1). Soluble dietary fibers produce viscous solutions that delay gastric emptying and absorption from the small intestine and tend to lower blood cholesterol level and

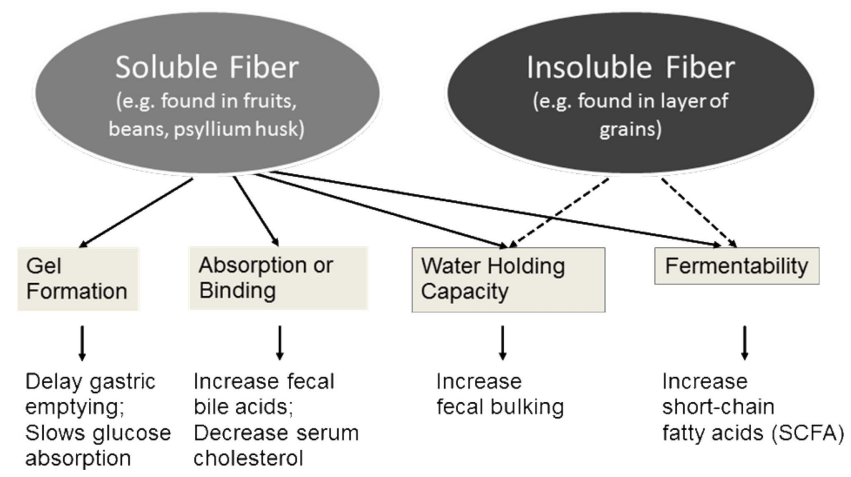

Fig. 1. Soluble and insoluble dietary fiber and their physiological functions.

Table 1. Most common dietary fibers, their primary sources and reported health benefits ${ }^{\mathrm{a}}$

\begin{tabular}{|c|c|c|}
\hline Dietary fiber components & Fiber sources & Health benefits \\
\hline Cellulose & $\begin{array}{l}\text { Primary component of the cell walls of most plants. Grains, fruits, } \\
\text { vegetables, and nuts. }\end{array}$ & Laxation \\
\hline Hemicellulose & $\begin{array}{l}\text { Forms about a third of the fiber in vegetables, fruits, legumes, and } \\
\text { nuts. Main dietary sources are cereal grains. }\end{array}$ & Laxation \\
\hline Pectin & $\begin{array}{l}\text { Found in cell walls and intracellular tissue of fruits and vegetables. } \\
\text { Sugar beets and potatoes are major sources. }\end{array}$ & $\begin{array}{l}\text { Blood lipid lowering } \\
\text { Attenuates blood glucose response }\end{array}$ \\
\hline Beta-glucan & Oats, barley & $\begin{array}{l}\text { Blood lipid lowering } \\
\text { Attenuates blood glucose response }\end{array}$ \\
\hline Resistant starch & Legumes, unripe banana & $\begin{array}{l}\text { Laxation } \\
\text { Attenuates blood glucose response }\end{array}$ \\
\hline $\begin{array}{l}\text { Inulin } \\
\text { Fructooligosaccharides }\end{array}$ & $\begin{array}{l}\text { Chicory root, Jerusalem artichoke, synthesized from simple carbo- } \\
\text { hydrates }\end{array}$ & $\begin{array}{l}\text { Laxation } \\
\text { Blood lipid lowering }\end{array}$ \\
\hline Gums & Gum guar, gum arabic, agar, carageenans, alginates & $\begin{array}{l}\text { Blood lipid lowering } \\
\text { Attenuates blood glucose response } \\
\text { May promote gut health }\end{array}$ \\
\hline Psyllium & Psyllium husk (plant) & $\begin{array}{l}\text { Laxation } \\
\text { Blood lipid lowering }\end{array}$ \\
\hline Chitin/Chitosan & Fungi and shellfish & Blood lipid lowering \\
\hline Lignin & Woody plant & \\
\hline
\end{tabular}

${ }^{\mathrm{a}}$ Cited from Anderson et al., 2009; Buttriss and Stokes, 2008; Tungland and Meyer, 2002 
glucose response (Anderson et al., 2004). Insoluble dietary fibers more help to accelerate rather than delay small bowel transit and have greater laxative effect than soluble fibers do (Anderson et al., 2004).

\section{Dietary fiber for health}

High-fiber diets have been associated with many health benefits such as lowering serum lipid concentration and blood pressure, helping with weight management, improving glucose and insulin response, maintaining a healthy digestive system, and reducing cancer risk (Buttriss and Stokes, 2008; Lattimer and Haub, 2010). Three physiological effects including laxation, blood cholesterol reduction, and glucose attenuation have been demonstrated for high-fiber diets over the past years. However, not all of the dietary fibers are able to perform each of these characteristics as shown in Table 1.

\section{Digestive health}

Dietary fiber components are not digested in the small intestine of humans. They are completely or partly fermented by the colonic microflora in the large intestine. Fermentation of dietary fiber components results in the formation of gases such as hydrogen, methane, and carbon dioxide and short-chain fatty acids (SCFA), primarily acetate, propionate, and butyrate. The available dietary fiber substrate in the colon results in the increase in the number of bacteria and in fecal mass. Increased fecal bulk helps to reduce colonic transit time which prevents constipation. The production of SCFA from the fermentation of dietary fiber components plays a key role in the health of colon. Propionate, in particular, was reported to lower cholesterol by suppressing cholesterol synthesis in the liver (Nishina and Freedland, 1990). Also, butyrate is the preferred sources for the growth and differentiation of colonic cells and possibly inhibits tumor growth (McIntyre et al., 1993). The formation of SCFA decreases the $\mathrm{pH}$ in the gut and thereby inhibits the growth of harmful bacteria while aiding the growth of bifidobacteria and lactic acid microflora (Scott et al., 2008).

\section{Cardiovascular health}

Intake of dietary fiber at recommended daily level is associated with lowering the risk of coronary heart disease, stroke, and peripheral vascular disease (Liu et al., 2000; Mann, 2007; Merchant et al., 2003). The mechanisms for the lowering effect of cardiovascular disease from the consumption of dietary fiber are unclear, but it is suggested that some dietary fiber, such as $\beta$-glucan, guar gum, pectin, and psyllium, can reduce blood cholesterol levels by lowering the reabsorption of bile acids and increasing fecal excretion of bile acids (Drzikova et al., 2005). Bile acids are synthesized in the liver from cholesterol. By binding bile acids with dietary fiber components, cholesterol in the liver can be converted to additional bile acids which are excreted, thus lowering cholesterol (Lunn and Buttriss, 2007).

\section{Prevention of diabetes}

Dietary fiber intake is inversely associated with risk of developing type 2 diabetes. Many studies reported a protective effect by whole grain foods (Mann, 2007; Venn and Mann, 2004). The protective effect resulted from the ability of dietary fiber to lower post-prandial glucose response (Meyer et al., 2000). Individuals consuming a diet with a high glycemic index (GI) and a low intake of cereal fiber have a risk of developing type 2 diabetes compared to those consuming a high-fiber diets with a low GI (Schulze et al., 2004).

\section{Prevention of obesity}

Food rich in dietary fiber help to promote satiety and a sense of fullness because of a high volume and a low energy density, thus preventing obesity (Buttriss and Stokes, 2008). Tucker and Thomas (2009) reported that the middle aged women consumed greater amounts of dietary fiber lost their weight caused by the decrease of body fat. The loss of weight was related to the intake level of dietary fiber in cereals, fruits and vegetables, and whole grains (Du et al., 2010; Koh-Banerjee et al., 2004; Tucker and Thomas, 2009). There is some evidence that several mechanisms may be involved like effects by gastric emptying, transit time to small intestine, and gut hormone production and these mechanisms may be influenced by types of dietary fiber (Buttriss and Stokes, 2008).

\section{Functional characteristics of dietary fiber}

Along with health and nutritional benefits, dietary fiber has various suitable functional properties which affect the quality and characteristics of food products. These functional properties should also be considered when various sources of dietary fiber incorporated to meat products. The major functional properties of dietary fiber are waterholding capacity, viscosity, gel-forming ability, and fatbinding capacity. 


\section{Water-holding capacity}

Dietary fiber generally has a high water-holding capacity. By hydrating a fiber, the water occupies the fiber pores and increases cooking yields, possibly reducing the caloric contents of meat products. Moreover, a high water-holding capacity can control moisture migration and ice crystal formation so that increasing the stability during freezing and thawing process (Gelroth and Ranhotra, 2001). The length, particle size, and porosity of dietary fiber components may affect the water-holding capacity and these can contribute to mouthfeel of the final products (Gelroth and Ranhorta, 2001; Tungland and Meyer 2002). The longer fibers which impart increased capability of water-holding to meat products can result in changes in texture depending on the level of fiber. The length and water-holding capacity of fiber is thus balanced against the textural changes (Bodner and Sieg, 2009).

\section{Viscosity}

Viscosity is a very important role of dietary fiber, providing rheological properties in food system including meat products. As the molecular weight or chain length of the fiber increases, the viscosity of fiber in solution increases. Long chain polymers, such as guar gum, locus bean gum, and $\beta$-glucan, exhibit high viscosity in the solution and these are used as thickening agents at low concentrations. Highly soluble fibers which have low viscosity, such as gum arabic, inulins, and oligosaccharides, are generally used to modify texture and water migration and to improve the marketability of the meat products as health-promoting or functional food products (Tungland and Meyer, 2002).

\section{Gel-forming ability}

The gel-forming ability of dietary fiber ingredients can contribute to increase the thickness or viscosity of products. Gelation is the association of polymer units to form a gel network with a firm three dimensional structure (Tungland and Meyer, 2002). This structure may stabilize or modify the physical structure of meat products thus helping to minimize shrinkage and improve product density. The composition and chemical properties provided by the various sources of dietary fiber can impact significantly on the ability of fiber to function as gelling agents. Blending of different sources of dietary fibers can also perform to develop a product specifically suited to the needs.

\section{Fat-binding capacity}

Alone or the combination of two or more dietary fiber ingredients can be used to reduce fat content in meat products (Decker and Park, 2010; Weiss et al., 2010) because they are fat dispersible and some also bind. The addition of dietary fiber ingredients that exhibit emulsion, lubricity, and gel texture can successfully replace some portion of fat in meat products.

\section{Application of dietary fiber in meat products}

As previously noted, dietary fiber provides various functional characteristics to food products along with health benefits. Dietary fiber as a functional ingredient is applicable to meat products (Table 2). Many studies reported that dietary fiber were incorporated with different types of meat products to increase cooking yield and reduce fat contents due to their water-holding and fatbinding properties (Garcia-Garcia and Totosau, 2008; Yilmaz, 2005). Dietary fiber from various sources alone or combined with other ingredients were formulated to lowfat and sodium-reduced meat products, largely ground and restructured meat products (Beriain et al., 2011; Garcia-Garcia and Totosau, 2008; Kumar and Sharma, 2004).

\section{Fibers from cereals}

Most usable dietary fiber sources for meat products were obtained from cereals, such as wheat, oat, rye, and rice (Table 2). Oats are well recognized as a whole-grain cereal, highly recommended as an important part of the daily diet. The use of oat fiber has gained a very positive attention to consumers because of health benefits associated with its consumption. Health benefits of oat-based food products are attributed to the soluble dietary fiber in oats, $(1 \rightarrow 3),(1 \rightarrow 4)-\beta$-D-glucan, referred to as $\beta$-glucan. The consumption of $\beta$-glucan attenuate postprandial glycemia, lowers cholesterol in the blood, and reduces colonic cancer risk (Butt et al., 2008; Lazaridou and Biliaderis, 2007). The U. S. Food and Drug Administration (FDA) has thus allowed a health claim stating that oat $\beta$ glucan at a level of $0.75 \mathrm{~g}$ per serving in a product, equal to a level of $3 \mathrm{~g} / \mathrm{d}$, may reduce cholesterol and lower the risk of coronary heart disease (FDA, 1997). These health benefits may be caused by the increase in viscosity formed by $\beta$-glucan, which is related to its concentration, structure, and molecular weight (Wood et al., 2000). Processing and cooking methods possibly influence the molecular, structural, and functional properties of $\beta$-glucan. Processing methods improved the physiological activity of $\beta$-glucan by increasing solubility and extractability (Regand et al., 2009) and reducing the molecular size of 


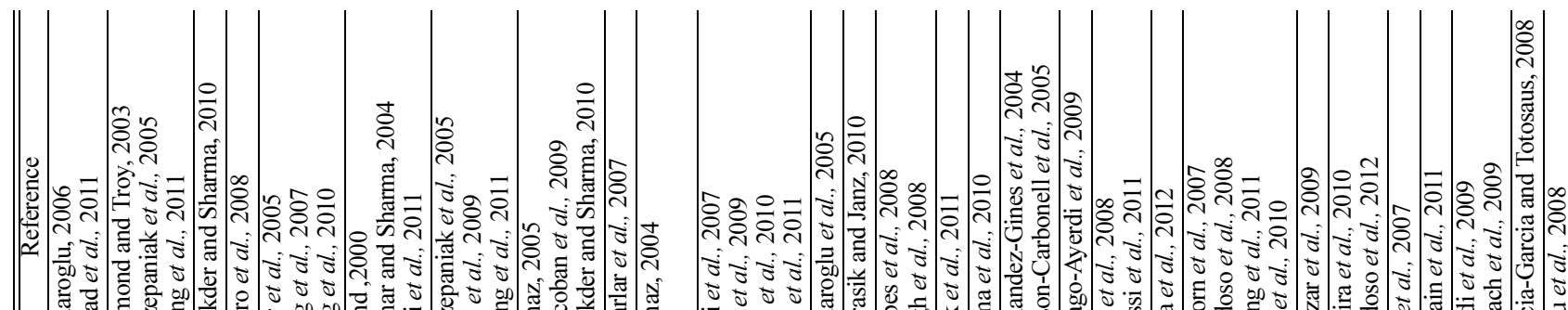

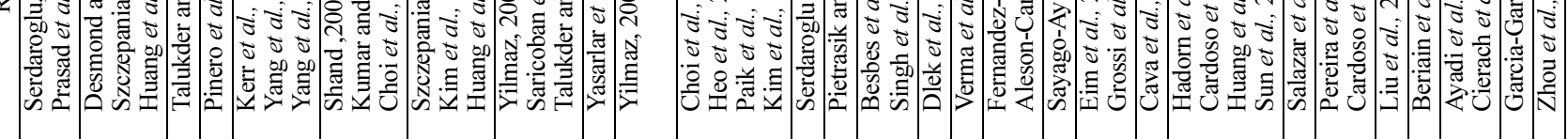

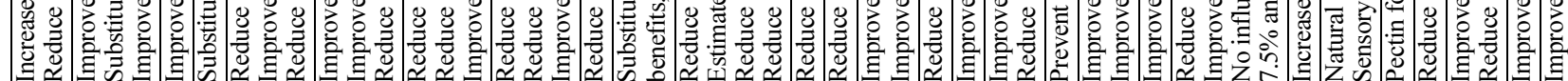

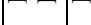

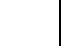


the polymer (Izydorczyk et al., 2008).

Due to the potential health benefits of oat fiber, especially $\beta$-glucan, it has been interested in using as a functional ingredient in common meat products. Functional characteristics of oat fiber, especially water-holding capacity, could potentially benefit meat products to decrease cooking losses and reduce fat content without loss of sensory acceptability in meat products, such as beef patties, pork sausages, and meatballs (Serdaroglu, 2006; Yasarlar et al., 2007; Yilmaz and Daglioglu, 2003). Different types of oats were added to different meat products. Oat flour itself was added to determine the characteristics of beef patties at 2 and 4\% (w/w) levels (Serdaroglu, 2006). The results indicated that oat flour at $4 \%$ addition helped to improve the cooking characteristics of beef patties without loss of sensory properties. Talukder and Sharma (2010) developed fiber-rich chicken meat patties containing 10 and $15 \%$ level of fiber by incorporated with oat bran. The addition of oat fiber provided the flavor, texture, and mouthfeel in pork sausages (Desmond and Troy, 2003). Pinero et al. (2008) utilized oat soluble fiber $\beta$ glucan. They added $\beta$-glucan (13.45\%) by using a commercial food product, called Nutrim-10 ${ }^{\circledR}$, to low-fat $(<10 \%$ fat) beef patties and compared physical, chemical, microbiological and sensory properties with control beef patties (20\% fat). The results showed that the addition of $\beta$-glucan improved cooking yield and fat retention and the water-holding capacity of $\beta$-glucan attributed to reach moisture content high in beef patties. Low-fat beef patties prepared with $\beta$-glucan lowered the degree of likeness in the taste but maintained the uniform tenderness without any noticeable loss of microbiological quality under frozen storage for $60 \mathrm{~d}$ in addition to providing physiological benefits of $\beta$-glucan. In the studies of Kerr et al. (2005) and Yang et al. (2007, 2010), hydrated oatmeal and oat flake were successfully incorporated to prepare low-fat pork sausages with optimum level of $15 \%$ to have sensory acceptability.

Barley is another excellent source of insoluble dietary fiber and soluble dietary fiber including $\beta$-glucan (Izydorczyk and Dexter, 2008). Because of health benefits of $\beta$-glucan, barley flour was incorporated to pork sausages (Choi et al., 2011; Shand, 2000). Kumar and Sharma (2004) reported that cooking yield, moisture retention, and dimensional parameters of low-fat ground pork patties were improved with increasing barley flour levels at 4, 7, and $10 \%$ and concluded that $4 \%$ inclusion of barley flour had greater sensory flavor and texture scores than 7 and 10\% levels.

Bran is the outer most layers of a cereal grain and has shown to decrease postprandial glucose levels, serum cholesterol, and colon cancer risk and to control body weight (Lattimer and Haub, 2010). Wheat bran, known as the best source of insoluble dietary fiber, was used as a fat substitute in the production of meatballs and beef patties (Saricoban et al., 2009; Yilmaz, 2005). Chicken meatballs prepared with wheat bran at 5,10 and 15\% levels increased cooking yield and firmness as well as insoluble fiber content (Talukder and Sharma, 2010). Saricoban et al. (2009) optimized processing variables including fat (10-30\%), wheat bran (5-15\%), and sodium chloride (0-2\%) of cooked beef patties by using response surface methodology. In the study of Yilmaz (2004), rye bran was added to meatballs as a fat substitute. The addition of rye bran at the levels of $5,10,15$, and $20 \%$ improved their nutritional value and reduced total fat including trans fatty acids. Another source of bran incorporated to meat products is rice bran. Choi et al. (2007) reported that meat batters containing rice bran had high $\mathrm{pH}$ values but lowered cooking loss and improved emulsion stability. Similar effects were also reported with semi-dried pork jerky and raw ground pork (Kim et al., 2011; Paik et al., 2010). Heo et al. (2009) investigated the growth of microorganisms related to spoilage in frankfurter sausage containing rice bran at $0,1,2$, and $3 \%$ to estimate the shelf-life of sausage. The addition of rice bran in sausage did not show significant differences in shelf-life as indicating no critical hazardous results in the growth of microorganisms caused by the addition of rice bran fiber.

\section{Fiber from legumes}

Legumes are important diet constituents, providing proteins and dietary fiber. Soybean and pea fiber have similar properties related to the fibers and are available either from their outer hulls or cotyledon portion. The extracted fibers from soybean and pea hulls are shorter and more cube-like rather than long thread-like structures observed in oat and wheat fiber (Bodner and Sieg, 2009). As a result, the water absorption capability of soybean and pea fiber tends to be lower than oat and wheat fiber. Pietrasik and Janz (2010) utilized pea starch and pea fiber-rich fractions to reduce fat contents of bologna sausage. The use of pea fibers as meat replacement in beef patties improved water-holding capacity so that increased cooking yield and minimized the production cost without degradation of sensory properties (Besbes et al., 2008). Roasted pea flour up to $10 \%$ level was incorporated to produce chicken nuggets and helped to improve emulsion stability without loss of sensory acceptability (Singh et 
al., 2008). Legume flours from blackeye bean, chick pea and lentil were successfully incorporated in production of meatballs with increased protein content (Serdaroglu et al., 2005).

\section{Fiber from fruits and vegetables}

Consumption of fruits and vegetables can help to prevent heart disease and stroke, control blood pressure, and prevent some types of cancer. These health benefits are mainly attributed to organic micronutrients such as fiber, carotenoids, polyphenols, tocopherols, vitamin $\mathrm{C}$, and other minor components (Schieber et al., 2001). During the processing of fruits and vegetables, abundant waste materials are produced and these by-products can be recovered and become high-added value products. Dietary fiber fractions of fruits and vegetable by-products have a great potential in the preparation of meat products as health promoting functional foods. Apple pulp was incorporated to prepare low-fat chicken nuggets at the levels of 8,10 and $12 \%$ (Verma et al., 2010). The $\mathrm{pH}$ of the chicken nugget product was lower than that of control but the addition of apple pulp significantly improved emulsion stability and cooking yield. The dietary fiber from citrus fruits contains high proportion of soluble dietary fiber so that used for meat products to promote health benefits. The important consideration when formulating meat products with citrus fibers is the taste profile because of its low $\mathrm{pH}$ which can cause acidic or bitter taste (Bodner and Sieg, 2009). Fernandez-Gines et al. (2004) successfully incorporated lemon albedo at 2.5 and $5 \%$ to sausages which had similar sensory properties to control sausage. The addition of grape antioxidant dietary fiber at the levels of $0.5,1,1.5$, and $2 \%$ to chicken breast hamburger decreased lightness and yellowness and increased in redness when cooked (Sayago-Ayerdi et al., 2009). When tomato fiber was incorporated in chopped cooked chicken products, the $\mathrm{pH}$ of chicken batters reduced in proportional to the level of fiber addition $(1,2$, and $3 \%$ ) and increased the redness of chicken product (Cava et al., 2012).

As a vegetable fiber, carrot fiber is a relatively new fiber to find the application in meat products and it has very high water absorption capability. Eim et al. (2008) formulated a dry-fermented sausage containing carrot dietary fiber at the levels of 3 to $12 \%(\mathrm{w} / \mathrm{w})$ and more than $3 \%$ fiber inclusion were not successful to have firm texture. In the study of Grossi et al. (2011), high pressure technology applied to the pork sausage incorporated with carrot dietary fiber. High pressure treatment and carrot fiber inclusion improved emulsion strength resulting in firm sausages but color was slightly changed.

\section{Soluble dietary fibers}

The functionality and application of soluble fibers in meat products include a wide range of fiber ingredients such as methylcellulose, carboxymethyl cellulose, hydrocolloid ingredients like xanthan and acacia gums (Bodner and Sieg, 2009). Inulin is a soluble fiber extracted by a washing process from chicory roots. It contains oligosaccharides and polysaccharides composed of fructose connected by $\beta-(2 \rightarrow 1)$ glycosidic bonds. Inulin added to meat products is mainly used for fat replacement because it forms a stable gel network which can mimic some textural properties of fat in low-fat meat products. By substituting fat with inulin for low-fat processed meat products, it is possible to achieve acceptable textural and sensory properties (Hadorn et al., 2007; Sun et al., 2010). Cardoso et al. (2008) formulated fish sausages containing chicory root inulin with the improvement of texture.

Another soluble dietary fiber used for meat products is fructooligosaccharides (FOS), recognized as a natural food ingredient and considered as a prototype pre-biotic which stimulates the growth of colonic microflora (Flamm et al., 2001). The effect of short-chain FOS on color, textural, and sensory properties in dry-fermented sausages was studied (Salazar et al., 2009). Physicochemical properties and microbial evolution during ripening of sausage were not affected by the presence of short-chain FOS but color was lighter than control. The presence of FOS reduced hardness of dry-fermented sausages to be easier to chew.

Other than those dietary fiber components, different fiber sources and theirs mixtures were incorporated into meat products. For examples, carrageenan and alginate from seaweeds were added to turkey meat sausages, pork sausages, and frankfurters with enhanced emulsion stability of products (Ayadi et al., 2009; Beriain et al., 2011; Cierach et al., 2009). In the study of Zhou et al. (2008), carrageenan, gellan gum and flaxseed gum were added together to produce starch-free emulsion-type sausage and the optimal contents of carrageenan, gellan gum, and flaxseed gum in the mixture for the sensory quality were $11-27 \%, 67-82 \%$, and $0-12 \%$, respectively.

\section{Future Prospects}

Dietary fiber from various sources, such as cereals, legumes, fruits and vegetable, can be successfully formu- 
lated to different types of meat products to improve nutritional values through fiber enrichment and fat reduction and to increase consumer acceptance. However, it is unclear if added dietary fiber to meat products provides the same health benefits as naturally occurring sources. In addition, bioavailability of added dietary fiber ingredients should be maintained during the processing and storage of meat products. Most conclusions are drawn from the fact that dietary fiber itself is beneficial to human health. Many studies only investigated the formulation of dietary fiber to produce final meat products. Therefore, further studies are needed to provide strong evidences to show the physiological effects of dietary fiber ingredients from different sources when formulated and processed meat products.

\section{Conclusion}

Dietary fiber has been used for food products because of their health benefits such as lowering serum lipid concentration, reducing glucose and insulin response, helping with weight management, maintaining a healthy digestive system, and reducing cancer risk. The addition of dietary fiber to meat products was considered to be health beneficial, thus possibly leading well-being of consumers. Moreover, functional characteristics of dietary fiber, mostly high water-holding capacity and fat-binding capacity, promoted their incorporation to meat products. Various sources of dietary fiber have been explored to formulate different types of meat products. The addition of dietary fiber enriched total dietary fiber content and reduced fat contents in meat products. The results suggested that dietary fiber can be used to meat products with their health benefits and functional properties. Further research is needed to understand their physiological effects not only when formulated but also during processing and storage.

\section{References}

1. AACC (2001) The definition of dietary fiber. Association of American Cereal Chemists Report. Cereal Food World 46, 112-126.

2. Aleson-Carbonell, L., Fernandez-Lopez, J., Perez-Alvarez, J. A., and Kuri, V. (2005) Functional and sensory effects of fiber-rich ingredients on breakfast fresh sausages manufacture. Food Sci. Technol. Int. 11, 89-97.

3. Anderson, J. W., Baird, P., Davis Jr., R. H., Ferreri, S., Knudtson, M., Koraym, A., Waters, V., and Williams C. L. (2009) Health benefits of dietary fiber. Nutr. Rev. 67, 188205.
4. Anderson, J. W., Randles, K. M., Kendall C. W. C., and Jenkins, D. J. A. (2004) Carbohydrate and fiber recommendations for individuals with diabetes: a quantitative assessment and meta-analysis of the evidence. J. Am. Coll. Nutr. 23, 517.

5. Ayadi, M. A., Kechaou, A., Makni, I., and Attia, H. (2009) Influence of carrageenan addition on turkey meat sausages properties. J. Food Eng. 93, 278-283.

6. Beriain, M. J., Gomez, I., Petri, E., Insausti, K., and Sarries, M. V. (2011) The effects of olive oil emulsified alginate on the physico-chemical, sensory, microbial, and fatty acid profiles of low-salt, inulin-enriched sausages. Meat Sci. 88, 189197.

7. Besbes, S., Attia, H., Deroanne, C., Makni, S., and Blecker, C. (2008) Partial replacement of meat by pea fiber: effect on the chemical composition, cooking characteristics and sensory properties of beef burgers. J. Food Quality 31, 480-489.

8. Biesalski, H. K. (2005) Meat as a component of a healthy diet - Are there any risks or benefits if meat is avoided in the diet? Meat Sci. 70, 509-524.

9. Birketvedt, G. S., Shimshi, M., Erling, T., and Florholmen, J. (2005) Experiences with three different fiber supplements in weight reduction. Med. Sci. Monitor 11, 15-18.

10. Bodner, J. M. and Sieg, J. (2009) Fiber. In: Ingredients in meat products: properties, functionality and application. Tarte, R. (ed) Springer Publishing, New York, NY, pp. 83-109.

11. Buttriss, J. L. and Stokes, C. S. (2008) Dietary fibre and health: an overview. British nutrition foundation. Nutr. Bulletin 33, 186-200.

12. Butt, M. S., Tahir-Nadeem, M., Khan, M. K. I., Shabir, R., and Butt, M. S. (2008) Oat: Unique among the cereals. Eur. J. Nutr. 47, 68-79.

13. Cardoso, C., Mendes, R., Pedro, S., and Nunes, M. L. (2008) Quality changes during storage of fish sausages containing dietary fiber. J. Aquat. Food Prod. Technol. 17, 73-95.

14. Cardoso, J. B. N., Henry, F. D. C., Almeida, S. B., Ferreira, K. S., and Ladeira, S. A. (2012) Characterization of cooked ham containing pectin and potassium chloride. J. Food Process. Pres. Online available, doi:10.1111/j.1745-4549.2011.00625x.

15. Cava, R., Ladero, L. Cantero, V., and Ramirez, M. R. (2012) Assessment of different dietary fibers (tomato fiber, beet root fiber, and inulin) for the manufacture of chopped cooked chicken products. J. Food Sci. 77, C346-C352.

16. Chang, H. C. and Carpenter, J. A. (1997) Optimizing quality of frankfurters containing oat bran and added water. J. Food Sci. 62, 194-202.

17. Choi, J.-W., Kim, S.-H., Mun, S., Lee, S.-J., Shim, J.-Y., and Kim, Y.-R. (2011) Optimizing the replacement of pork fat with fractionated barley flour paste in reduced-fat sausage. Food Sci. Biotechnol. 20, 687-694.

18. Choi, Y. S., Jong, Y. J., Choi, J. H., Doo, J. H., Hack, Y. K., Lee, M. A., Shim, S. Y., Paik, H. D., and Kim, C. J. (2007) Quality characteristics of meat batters containing dietary fiber extracted from rice bran. Korean J. Food Sci. An. 27, 228-234.

19. Cierach, M., Modzelewska-Kapitula, M., and Szacilo, K. 
(2009) The influence of carrageenan on the properties of low-fat frankfurters. Meat Sci. 82, 295-299.

20. Cofrades, S., Guerra, M. A., Carballo, J., Fernandez-Martin, F., and Jimenez-Colmenero, F. (2000) Plasma protein and soy fiber content effect on bologna sausage properties as influenced by fat level. J. Food Sci. 65, 281-287.

21. Decker, E. A. and Park, Y. (2010) Healthier meat products as functional foods. Meat Sci. 86, 49-55.

22. Desmond, E. M. and Troy, D. J. (2003) Sensory and physical characteristics of pork sausages manufactured with dietary fiber. Irish J. Agric. Food Res. 42, 161.

23. Dlek, M., Polat, H., Kezer, F., and Korcan, E. (2011) Application of locust bean gum edible coating to extend shelf life of sausages and garlic-flavored sausage. J. Food Process. Pres. 35, 410-416.

24. Du, H. D., van der A, D. L., Boshuizen, H. C., Forouhi, N. G., Wareham, N. J., Halkjaer, J., Tjonneland, A., Overvad, K., Jakobsen, M. U., Boeing, H., Buijsse, B., Masala, G., Palli, D., Sorensen, T. I. A., Saris, W. H. M., and Feskens, E. J. M. (2010) Dietary fiber and subsequent changes in body weight and waist circumference in European men and women. $\mathrm{Am}$. J. Clin. Nutr. 91, 329-336.

25. Drzikova, B., Donowski, G., Gebhardt, E., and Habel, A. (2005) The composition of dietary fiber-rich extrudates from oat affects bile acid binding and fermentation in vitro. Food Chem. 90, 181-192.

26. Eim, V. S., Simal, S., Rossello, C., and Femenia, A. (2008) Effects of addition of carrot dietary fiber on the ripening process of a dry fermented sausage (sobrassada). Meat Sci. 80, 173-182.

27. FDA. (1997) Food labeling: Health claims; oat and coronary heart disease. Final rule. Federal Register 62, Department of Health and Human Services. US Food and Drug Administration: Washington, D.C. pp. 3584-3681.

28. Fernandez-Gines, J. M., Fernandez-Lopez, J., Sayas-Barbera, E., Sendra, E., and Perez-Alvarez, J. A. (2004) Lemon albedo as a new source of dietary fiber: Application to bologna sausages. Meat Sci. 67, 7-13.

29. Flamm, G., Glinsmann, W., Kritchevsky, D., Prosky, L., and Roberfroid, M. (2001) Inulin and oligofructose as dietary fiber: a review of the evidence. Crit. Rev. Food Sci. Nutr. 41, 353-362.

30. Garcia-Garcia, E. and Totosaus, A. (2008) Low-fat sodiumreduced sausages: Effect of the interaction between locust bean gum, potato starch and kappa-carrageenan by a mixture design approach. Meat Sci. 78, 406-413.

31. Gelroth, J. and Ranhotra, G. S. (2001) Food Uses of Fiber. In: Handbook of dietary fiber. Dreher, M. L. and Cho, S. S. (eds) Marcel Dekker Inc., New York, NY. pp. 435-451.

32. Grossi, A., Soltoft-Jensen, J., Knudsen, J. C., Christensen, M., and Orlien, V. (2011) Synergistic cooperation of high pressure and carrot dietary fiber on texture and color of pork sausages. Meat Sci. 89, 195-201.

33. Hadorn, R., Piccinali, P., and Suter, M. (2007) Fat reduction with inulin in water-boiled sausages. Revue Suisse D Agriculture 39, 244-248.
34. Heo, C., Kim, H. W., Choi, Y.S., Kim, C.-J., and Paik, H.-D. (2009) Shelf-life estimation of frankfurter sausage containing dietary fiber from rice bran using predictive modeling. Korean J. Food Sci. Ani. Resour. 29, 47-54.

35. Huang, S. C., Tsai, Y. F., and Chen, C. M. (2011) Effects of wheat fiber, oat fiber, and inulin on sensory and physicchemical properties of Chinese-style sausages. Asian-Australasian J. Anim. Sci. 24, 875-880.

36. Izydorczyk, M. S. and Dexter, J. E. (2008) Barley $\beta$-glucans and arabinoxylans: Molecular structure, physicochemical properties, and uses in food products - a review. Food Res. Int. 41, 850-868.

37. Jimenez-Colmenero, F.,Carballo, J., and Cofrades, S. (2001) Healthier meat and meat products: their role as functional foods. Meat Sci. 59, 5-13.

38. Keenan, J. M., Pins, J. J., Frazel, C., Moran, A., and Turnquist, L. (2002) Oat ingestion reduces systolic and diastolic blood pressure in patients with mild or borderline hypertension: a pilot trial. J. Fam. Practice 51, 369-375.

39. Kerr, W. L., Wang, X., and Choi, S. G. (2005) Physical and sensory characteristics of low-fat Italian sausage prepared with hydrated oat. J. Food Quality 28, 62-77.

40. Kim, H.-W., Choi, J.-H., Choi, Y.-S., Han, D.-J., Kim, H.-Y., Lee, M.-A., Shim, S.-Y., and Kim, C.-J. (2009) Effects of wheat fiber and isolated soy protein on the quality characteristics of frankfurter-type sausages. Korean J. Food Sci. An. 29, 475-481.

41. Kim, H. W., Choi, Y. S., Choi, J. H., Han, D. J., Kim, H. Y., Hwang, K. E., Song, D. H., and Kim, C. J. (2011). Effects of rice bran fiber on changes in the quality characteristics of raw ground pork during chilled storage. Korean J. Food Sci. Ani. Resour. 31, 339-348.

42. KNS. (2010) Dietary reference intakes for Koreans. The Korean Nutrition Society. Seoul, Korea. p. 3.

43. Koh-Banerjee, P., Franz, M. V., Sampson, L., Liu, S. M., Jacobs, D. R., Spiegelman, D., Willett, W., and Rimm, E. (2004) Changes in whole-grain, bran, and cereal fiber consumption in relation to 8-year weight gain among men. $\mathrm{Am}$. J. Clin. Nutr. 80, 1237-1245.

44. Kumar, M. and Sharma, B. D. (2004) Quality and storage stability of low-fat pork patties containing barley flour as fat substitute. J. Food Sci. Technol. 41, 496-502.

45. Lattimer, J. M. and Haub, M. D. (2010) Dietary fiber and its components on metabolic health. Nutrients 2, 1-26.

46. Lazaridou, A. and Biliaderis, C. G. (2007) Molecular aspects of cereal $\beta$-glucan functionality: Physical properties, technological applications and physiological effects. J. Cereal Sci. 46, 101-118.

47. Liu, L., Kerry, J. F., and Kerry, J. P. (2007) Application and assessment of extruded edible casings manufactured from pectin and gelation/sodium alginate blends for use with breakfast pork sausage. Meat Sci. 75, 196-202.

48. Liu, S., Manson, J. E., and Stampfer, M. J. (2000) Whole grain consumption and risk of ischemic stroke in women: a prospective study. J. Am. Med. Assoc. 284, 1584-1540.

49. Lunn, J. and Buttriss, J. L. (2007) Carbohydrates and dietary 
fiber. Nutr. Bulletin 32, 21-64.

50. Mann, J. (2007) Dietary carbohydrate: relationship to cardiovascular disease and disorders of carbohydrate metabolism. Eur. J. Clin. Nutr. 61, 100-111.

51. McIntyre, A., Gibson, P. R., and Young, G. P. (1993) Butyrate production from dietary fiber and protection from large bowel cancer in a rat model. Gut 34, 38.

52. Mendoza, E., Garcia, M. L., Casas, C., and Selgas, M. D. (2001) Inulin as fat substitute in low fat, dry fermented sausages. Meat Sci. 57, 387-393.

53. Merchant, A. T., Hu, F. B., Spiegelman, D., Willett, W. C., Rimm, E. B., and Ascherio, A. (2003) Dietary fiber reduces peripheral arterial disease risk in men. J. Nutr. 133, 36583663.

54. Meyer, K. A., Kushi, L H., Jacobs, D. R., Slavin, J., Sellers, T. A., and Folsom, A. R. (2000) Carbohydrates, dietary fiber, and incident type 2 diabetes in older women. Am. J. Clin. Nutr. 71, 921-930.

55. Nishina, P. M. and Freedland, R. A. (1990) Effects of propionate on lipid biosynthesis in isolated rat hepatocytes. $J$. Nutr. 120, 668-673.

56. Paik, H. D., Kim, C. J., Kim, T. H., Choi, J. H., Han, D. J., Choi, Y. S., Kim, H. Y., Lee, M. A., and Shim, S. Y. (2010) Physicochemical properties and sensory characteristics of semi-dried pork jerky with rice bran fiber. Korean J. Food Sci. An. 30, 966-974.

57. Pereira, C. M., Marques, M. F., Hatano, M. K., and Castro, I. A. (2010) Effect of the partial substitution of soy protein by highly methyl-esterified pectin on chemical sensory characteristics of sausages. Food Sci. Technol. Int. 16, 401-407.

58. Pietrasik, Z. and Janz, J. A. M. (2010) Utilization of pea flour, starch-rich and fiber-rich fractions in low fat bologna. Food Res. Int. 43, 602-608.

59. Pinero, M. P., Parra, K., Huerta-Leidenz, N., de Moreno, L. A., Ferrer, M., Araujo, S., and Barboza, Y. (2008) Effect of oat's soluble fiber (beta-glucan) as a fat replacer on physical, chemical, microbiological and sensory properties of low-fat beef patties. Meat Sci. 80, 675-680.

60. Prasad, B., Rashmi, M. D., Yashoda, K. P., and Modi, V. K. (2011) Effect of casein and oat flour on physicochemical and oxidative processes of cooked chiken kotfa. J. Food Process. Pres. 35, 359-368.

61. Regand, A., Tosh, S. M., Wolever, T. M. S., and Wood, P. J. (2009) Physicochemical properties of $\beta$-glucan in differently processed oat foods influence glycemic response. J. Agric. Food Chem. 57, 8831-8838.

62. Salazar, P., Garcia, M. L., and Selgas, M. D. (2009) Shortchain fructooligosaccharides as potential functional ingredient in dry fermented sausages with different fat levels. Int. J. Food Sci. Technol. 44, 1100-1107.

63. Saricoban, C., Yilmaz, M. T., and Karakaya, M. (2009) Response surface methodology study on the optimization of effects of fat, wheat bran and salt on chemical, textural and sensory properties of patties. Meat Sci. 83, 610-619.

64. Sayago-Ayerdi, S. G., Brenes, A., and Goni, I. (2009) Effect of grape antioxidant dietary fiber on the lipid oxidation of raw and cooked chicken hamburgers. LWT-Food Sci. Technol. 42, 971-976.

65. Schieber, A., Stingtzing, F. C., and Carle, R. (2001) By-products of plant food processing as a source of functional compounds-recent developments. Trends Food Sci. Technol. 12, 401-413.

66. Schulze, M. B., Liu, S., Rimm, E. B., Manson, J. E., Willett, W. C., and Hu, F. B. (2004) Glycemic index, glycemic load, and dietary fiber intake and incidence of type 2 diabetes in younker and middle aged women. Am. J. Clin. Nutr. 80, 348356.

67. Scott, K. P., Duncan, S. H., and Flint, H. J. (2008) Dietary fiber and the gut microbiota. Nutrition Bulletin 33, 201-211.

68. Serdaroglu, M., Yildiz-Turp, G., and Abrodimov, K. (2005) Quality of low fat meatballs containing legume flours as extenders. Meat Sci. 70, 99-105.

69. Serdaroglu, M. (2006) The characteristics of beef patties containing different levels of fat and oat flour. Int. J. Food Sci. Technol. 41, 147-153.

70. Shand, P. J. (2000) Textural, water holding and sensory properties of low-fat pork bologna with normal or waxy starch hull-less barley. J. Food Sci. 65, 101-107.

71. Singh, O. P., Singh, J. N., Bharti, M. K., and Kumari, S. (2008) Refrigerated storage stability of chicken nuggets containing pea flour. J. Food Sci. Technol. 45, 460-462.

72. Sun, C. Y., Wang, J., Zhang, K. S., Sun, C. Y., Wang, J., and Zhang, K. S. (2010) Process research on inulin as the fat substitute. Food Fermentation Technol. 46, 56-60.

73. Szczepaniak, B., Ptotrowska, E., Dolata, W., and ZawirskaWojtasiak, R. (2005) Effect of partial fat substitution with dietary fiber on sensory properties comminuted sausages Part I. What and oat fiber. Polish J. Food Nutr. Sci. 14, 309314.

74. Talukder, S. and Sharma, D. P. (2010) Development of dietary fiber rich chicken meat patties using wheat and oat bran. J. Food Sci. Technol. 47, 224-229.

75. Tucker, L. A. and Thomas, K. S. (2009) Increasing total fiber intake reduces risk of weight and fat gains in women. J. Nutr. 139, 576-581.

76. Tungland, B. C. and Meyer. D. (2002) Nondigestible oligoand polysaccharides (dietary fiber): their physiology and role in human health and food. Compr. Rev. Food Sci. F. 1, 1-22.

77. U.S. Department of Agriculture. (2010) U.S. Department of Health and Human Services. Dietary Guidelines for Americans. Washington D.C.

78. Venn, B. J. and Mann, J. (2004) Cereal grains, legumes and diabetes. Eur. J. Clin. Nutr. 58, 1143-1161.

79. Verma, A. K., Sharma, B. D., and Banerjee, R. (2010) Effect of sodium chloride replacement and apple pulp inclusion on the physico-chemical, textural and sensory properties of low fat chicken nuggets. LWT-Food Sci. Technol. 43, 715-719.

80. Weiss, J., Gibis, M., Schuh V., and Salminen, H. (2010) Advances in ingredient and processing systems for meat and meat products. Meat Sci. 86, 196-213.

81. Wood, P. J., Beer, M. U., and Butler, G. (2000) Evaluation of role of concentration and molecular weight of oat $\beta$-glucan 
in determining effect of viscosity on plasma glucose and insulin following an oral glucose load. Brit. J. Nutr. 84, 1934.

82. Yang, H.-S., Choi, S.-G., Jeon, J.-T., Park, G.-B., and Joo, S.T. (2007) Textural and sensory properties of low fat pork sausages with added hydrated oatmeal and tofu as texture-modifying agents. Meat Sci. 75, 283-289.

83. Yang, H.-S., Kim, G.-D., Choi, S.-G., and Joo, S.-T. (2010) Physical and sensory properties of low fat sausage amended with hydrated oat meal and various meats. Korean J. Food Sci. An. 20, 365-372.

84. Yasarlar, E. E., Daglioglu, O., and Yilmaz, I. (2007) Effects of cereal bran addition on chemical composition, cooking characteristics and sensory properties of Turkish meatballs. Asian J. Chem. 19, 2353-2361.
85. Yilmaz, I. (2004) Effects of rye bran addition on fatty acid composition and quality characteristics of low-fat meatblass. Meat Sci. 67, 245-249.

86. Yilmaz, I. (2005) Physicochemical and sensory characteristics of low fat meatballs with added wheat bran. J. Food Eng. 69, 369-373.

87. Yilmaz, I. and Daglioglu, O. (2003) The effect of replacing fat with oat bran on fatty acid composition and physicochemical properties of meatballs. Meat Sci. 65, 819-823.

88. Zhou, W. W., Meng, L., Li, X., Ma, L., and Dai, R. (2008) Effect of the interaction between carrageenan, gellan gum and flaxseed gum on quality attributes of starch-free emulsion-type sausage. J. Muscle Foods 21, 255-267.

$\overline{\text { (Received 2012.7.14/Revised 2012.10.16/Accepted 2012.10.23) }}$ 